\title{
Cáncer oral: Puesta al día
}

\section{Update in oral cancer}

\author{
García-García V*, Bascones Martínez A**
}

\section{RESUMEN}

Se presenta una revisión bibliográfica sobre los aspectos clínicos e histológicos de mayor relevancia en relación al cáncer oral. Asimismo se ahonda en su posible etiología y mecanismo a nivel molecular junto con la manifestación de la importancia del papel del odontólogo en su detección precoz..

Palabras clave: Cáncer oral, factores de riesgo, carcinogénesis, displasia epitelial.

\section{SUMMARY}

A review about the most important clinical and histological aspects in relation with oral cancer is presented. In addition a summary about the possible etiology and molecular mechanism will be described alltogether with the main role of the dentist in the early detection.

Key words: Oral cancer, risk factors, carcinogenesis, epithelial dysplasia.

Fecha de recepción: 17 de septiembre de 2008.

Aceptado para publicación: 22 de septiembre de 2008.

* $\quad$ Máster de Periodoncia e Implantes U.C.M.

** Catedrático de Medicina Oral, Periodoncia e Implantes.

García-García V, Bascones Martínez A. Cáncer oral: Puesta al día. Av. Odontoestomatol 2009; 25 (5): 239-248.

\section{CONCEPTOS GENERALES}

La palabra cáncer se emplea para referirse a un grupo de más de 100 enfermedades distintas con más de 1,000 variedades histopatológicas que comparten como característica común una proliferación anormal y descontrolada de células que invaden tejidos y órganos próximos y distantes y que, si no son tratadas a tiempo, ocasionan la muerte de los individuos en cuyo seno se desarrollan. El primero en hablar de cáncer fue Hipócrates y probablemente dicho término deriva del latín cangrejo, ya que el tumor se adhiere a todo lo que agarra con la misma obstinación que un cangrejo. El término carcinoma hace referencia al cáncer derivado de las células epiteliales (90\% de los casos de cánceres) (1). Hablamos de neoplasia cuando se produce una prolife- ración incontrolada de células somáticas producto de un cambio irreversible en las mismas. El exceso de tejido persiste aunque cese el estímulo. Las neoplasias pueden ser benignas, si son localizadas y no invaden los tejidos adyacentes ni se diseminan por el resto del cuerpo, o malignas, si invaden y destruyen tejidos y son capaces de diseminarse (2).

Así, entenderemos por cáncer oral aquellas neoplasias malignas desarrolladas a partir de la mucosa oral, la cual comprende las siguientes áreas:

- Labios y comisura labial.

- Mejillas.

- Suelo bucal y lengua móvil.

- Paladar duro.

- Istmo de las fauces. 
Entre los tipos de mucosa oral tenemos la mucosa masticatoria que incluye la encía y el paladar duro, la mucosa especializada focalizada en la cara dorsal de la lengua y la mucosa de revestimiento que abarca la cara interna de los labios, mejillas, vestíbulos, suelo de la boca, cara ventral lengua y velo del paladar (3).

\section{CLASIFICACIÓN DE LOS TUMORES MALIGNOS DE LOS TEJIDOS BLANDOS ORALES}

En función del tejido del que derivan encontramos:

a) Tumores malignos derivados del epitelio:

- Carcinoma oral de células escamosas o epidermoide (90\%).

- Carcinoma verrucoso.

- Carcinoma de células fusiformes.

- Melanoma.

- Adenocarcinoma, carcinoma mucoepidermoide.

- Carcinoma basocelular.

Brevemente describiremos cada uno de los tipos cancerosos derivados del epitelio:

El carcinoma oral de células escamosas o epidermoide es el cáncer que comienza en las células escamosas, encontrándose éstas en piel, revestimiento de los órganos huecos del cuerpo y en los pasajes de los tractos respiratorio y digestivo. Supone el $4 \%$ de todos los cánceres del organismo y el $90 \%$ de todos los cánceres de la cavidad oral (Figura 1).

El carcinoma verrucoso consiste en un carcinoma epidermoide descrito aparte por ser su comportamiento distinto, ya que poseen menor grado de malignidad, tienen un crecimiento lento y este no es invasivo.

El carcinoma de células fusiformes comprende un tumor bimórfico que muestra en la superficie focos de carcinoma epidermoide y más en profundidad células fusiformes.

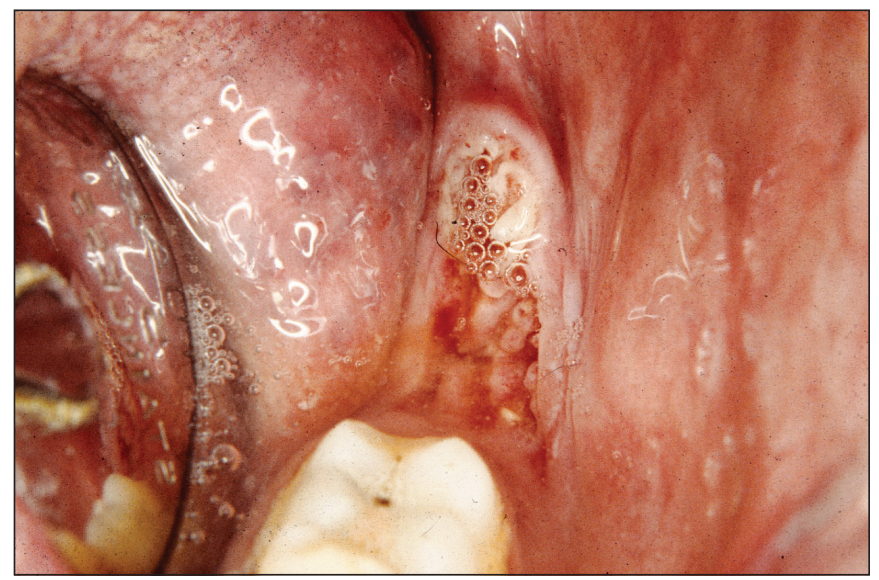

Fig. 1. Carcinoma epidermoide en trígono retromolar. Por cortesía del Dr. Antonio Bascones Martínez.

El melanoma es una neoplasia de los melanocitos de alto grado de malignidad que es poco frecuente pero importante ya que podría confundirse con una pigmentación de la mucosa oral.

El adenocarcinoma o carcinoma mucoepidermoide define un cáncer que afecta a las glándulas salivales (Figura 2).

El carcinoma basocelular consiste en un cáncer que se origina en la capa más profunda de la epidermis (estrato basal), sobretodo en áreas expuestas al sol (Figura 3).

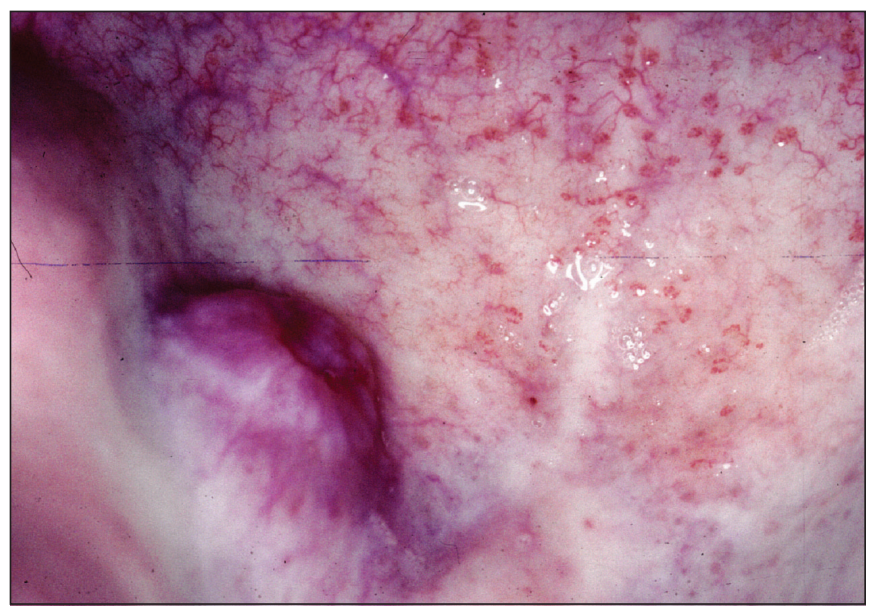

Fig. 2. Carcinoma mucoepidermoide en paladar. Por cortesía del Dr. Antonio Bascones Martínez. 


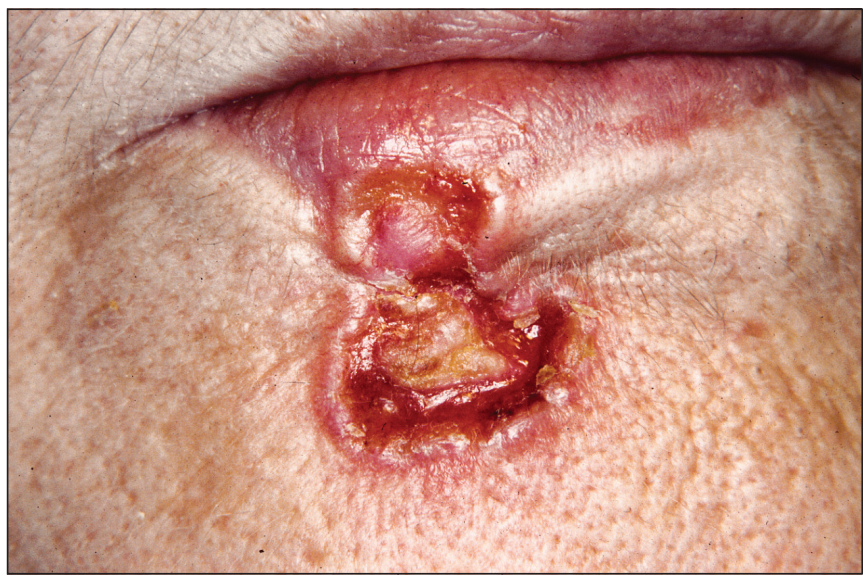

Fig. 3. Carcinoma basocelular de labio y piel de barbilla. Cedida por el Dr. Antonio Bascones Martínez.

b) Tumores malignos derivados del tejido conectivo. En función de las células conectivas de las que derivan se dividen en:

- Fibrosarcoma: derivado de fibroblastos.

- Fibrohistocitoma maligno: derivado de los fibroblastos e histiocitos malignos.

- Liposarcoma: derivado de los adipocitos.

- Angiosarcoma: derivado de las células endoteliales de los vasos sanguíneos y linfáticos.

- Neurosarcoma: derivado de la cubierta de los nervios periféricos.

- Rabdomiosarcomas: derivado de células del músculo estriado.

- Leiomiosarcomas: derivado de células del músculo liso, son poco frecuentes en la cavidad oral.

c) Metástasis en las partes blandas de la cavidad oral: son poco frecuentes en la mucosa oral, ya que de todas las neoplasias del organismo sólo un $1 \%$ metastatizan en mucosa oral, el $90 \%$ en huesos maxilares y el $10 \%$ en partes blandas. Los tumores primarios suelen localizarse en pulmón, riñón e hígado.

d) Neoplasias del sistema inmune con afectación oral:

- Linfoma No Hodgkin: es una neoplasia de los linfocitos y sus precursores.

- Plasmocitoma-mieloma múltiple: comprende una neoplasia maligna hematológica con proliferación de células plasmáticas y con afectación múltiple de la médula ósea (4).

\section{EPIDEMIOLOGÍA DEL CÁNCER ORAL}

El cáncer de cabeza y cuello es el $6^{\circ}$ cáncer humano más frecuente (5). El 3\% de todos los cánceres se localizan en la cavidad oral (6). No obstante existe una variabilidad geográfica con una mayor prevalencia en América del Sur, Sudeste asiático y sobretodo en la India, en la cual el cáncer oral representa el $40 \%$ de todos los tumores malignos (7).

Cada año se diagnostican en el mundo más de 575.000 casos nuevos de cáncer oral (8). La incidencia en España es de 5,7-12,9 casos por 100.000 hombres/año y de 0,6-2,1 casos por 100.000 mujeres/año, aunque estas cifras se están igualando con la adopción por parte de la mujer de hábitos nocivos similares a los de los hombres (9).

En cuanto a la edad, el $90 \%$ de los cánceres orales se diagnostican en mayores de 40 años, y más del $50 \%$ en individuos de más de 65 años $(10,11)$. Recientemente se ha observado un aumento en la incidencia de esta enfermedad en menores de 40 años lo que podría estar asociado a una infección por el virus del papiloma humano (16 y 18) (12).

Las principales localizaciones son lengua y suelo de boca en Europa y el norte de América y la mucosa yugal en la India $(13,14)$.

En referencia a la histología el 90\% de los carcinomas orales son del tipo carcinoma oral de células escamosas (13).

La supervivencia a los 5 años es del 40-56\% aunque varía según el tipo de cáncer:

- $70 \%$ Cáncer labial

- $30 \%$ Otras localizaciones orales (4).

\section{ETIOLOGÍA DEL CÁNCER ORAL}

Podríamos empezar diciendo que la etiología del cáncer oral es desconocida, sin embargo, existen 
una serie de factores de riesgo que podrían actuar como agentes carcinogenéticos favoreciendo el desarrollo de la enfermedad. Entre éstos, destacamos:

\section{Tabaco}

El tabaco es el principal factor de riesgo asociado al desarrollo de lesiones premalignas y del cáncer oral, en especial del Carcinoma Oral de Células Escamosas (COCE). 8 de cada 10 pacientes con cáncer oral son fumadores de tabaco en sus diversas formas: cigarrillos, puros, tabaco de mascar, tabaco en pipa, etc. Los componentes más carcinogénicos del tabaco son la N-nitroso-nor-nicotina, hidrocarburos aromáticos polinucleares y el polonium, siendo perjudiciales localmente y favoreciendo la absorción de sustancias carcinógenas (15).

Hay multitud de estudios transversales en los que se ha visto la asociación entre el tabaco y la aparición del cáncer oral, no obstante, los estudios más valiosos son los que examinan longitudinalmente el efecto del tabaco. Entre estos destaca el maravilloso estudio longitudinal a 10 años en una población de la India publicado por Gupta y cols. en 1980. En él analizan la historia natural de las lesiones precancerosas en relación al consumo de tabaco y confirman el papel del tabaco como factor de riesgo para la malignización de las lesiones orales. Estos autores observaron una incidencia mayor y una evolución más agresiva en aquellas personas con hábito de fumar invertido (16).

Además, se ha observado un efecto sinérgico entre el tabaco y el alcohol (17-19).

\section{Alcohol}

El etanol puro, por sí mismo, no es una sustancia carcinogénica, sin embargo, se asocia a sustancias carcinógenas que actúan como desencadenantes de la acción tóxica del alcohol. Así, el alcohol ejercería un efecto cáustico aumentando la permeabilidad de la mucosa oral y permitiendo el paso de otros carcinógenos como el tabaco. Entre las lesiones ocasionadas por el alcohol se encuentran:
- Desprendimiento del epitelio.

- Ulceraciones en la mucosa.

- Gingivitis.

- Petequias.

- Lesiones blancas (20).

Se ha investigado la asociación entre el cáncer oral y el uso de enjuagues orales con alto contenido en alcohol basándose en la hipótesis de que la permanencia del alcohol en contacto con la mucosa oral durante un mayor tiempo que al injerir una bebida alcohólica podría hacer pensar en un posible efecto nocivo a partir de un mecanismo local. Sin embargo, no se ha podido confirmar una relación causal entre el uso de colutorios y el desarrollo de cáncer oral, pero, por otro lado, no se justificaría el empleo de alcohol en los colutorios orales (21).

\section{Dieta}

Algunos nutrientes y hábitos alimenticios están asociados al desarrollo de muchas enfermedades como el cáncer oral (22):

- Las grasas no muestran correspondencia con el cáncer oral, pero sí con el cáncer de intestino, páncreas e hígado.

- Las frutas y verduras son ricas en micronutrientes y tienen un efecto antioxidante y protector frente al cáncer oral. Son varios los estudios en relación al licopeno, sustancia contenida en el tomate y liberada tras la cocción del mismo que actuaría como antioxidante (23).

- El consumo excesivo de carnes rojas fritas o cocinadas con condimentos picantes favorece el desarrollo del cáncer oral, ya que desprenden sustancias carcinógenas como las aminas heterocíclicas.

En la tabla 1 se observan una serie de recomendaciones de la Organización Mundial de la Salud (O.M.S).

\section{Inmunosupresión}

El aumento del cáncer oral en jóvenes podría explicarse por el problema de la inmunosupresión crónica asociada al VIH (24). 


\section{TABLA 1.- RECOMENDACIONES SOBRE DIETA Y CÁNCER (OMS)}

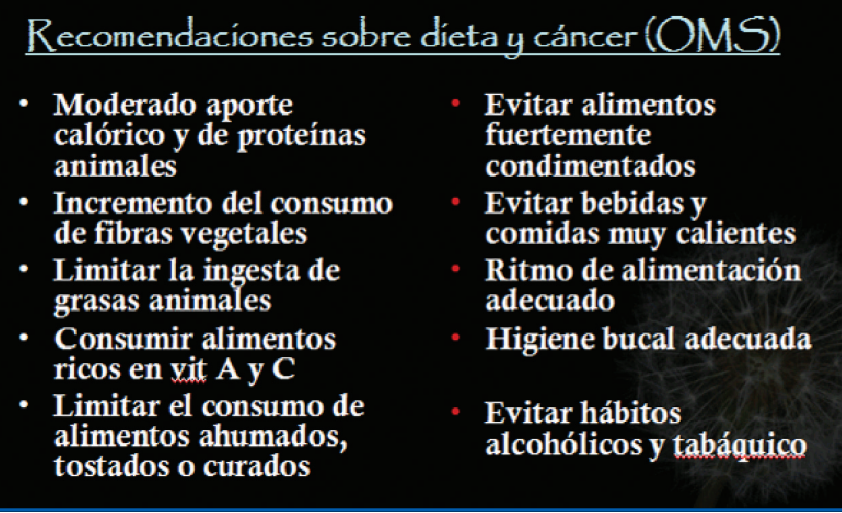

\section{Factores dentales}

Resulta difícil de valorar la posible relación existente entre la presencia de una dentición en mal estado, prótesis mal adaptadas, prótesis antiguas y dientes rotos o astillados y la existencia de cáncer oral. Sin embargo, hay algunos estudios que avalan esta relación $(25,26)$.

\section{Infecciones}

En relación a las infecciones virales, no está claro el papel del Virus del Papiloma Humano en relación con el cáncer oral, ya que las publicaciones desde 1996 hasta el 2003 presentan un rango de porcentajes que oscila de forma excesivamente amplia del $0 \%$ al $91 \%$. Esta variedad en los resultados podría deberse a deficiencias metodológicas como la existencia de un tamaño muestral pequeño, la ausencia de un grupo control, la utilización de métodos de detección de diferentes sensibilidades para la detección viral, la baja carga viral que en algunos casos que dificulta la detección, la ausencia de control de cofactores asociados como tabaco, alcohol, edad, sexo, localización anatómica, etc (13).

En relación a las infecciones bacterianas se ha visto relación con sífilis y glositis sifilítica pero más bien debido a los fármacos empleados en el tratamiento de estas entidades como las sales de arsénico u otros metales pesados (13).
En relación a las infecciones micóticas, no está claro si las cándidas son elementos sobreinfectantes de la lesión o agentes específicos productores de la misma (13).

\section{Radiaciones}

Las personas con poca pigmentación en la piel que estén sometidas a una exposición solar ocupacional y prolongada presentan mayor riesgo de desarrollar un carcinoma epidermoide de labio. El labio pasa por una serie de cambios preneoplásicos que progresan más intensamente cuando la dosis de radiación actínica se acumula y cuando se va envejeciendo. A estos cambios se les denomina queilitis actínica. Si continuara la exposición se podría acabar desarrollando un carcinoma epidermoide (27).

Por otro lado, se ha visto relación entre las radiaciones ionizantes y un aumento del riesgo de neoplasias de glándulas salivares (13).

\section{Factores socioeconómicos y ocupacionales}

Se ha podido constatar una prevalencia del cáncer oral en trabajadores de la rama textil, comerciantes de alcohol, trabajadores de imprentas, manipuladores de material fosforescente para la fabricación de las esferas de los relojes y también en las clases sociales más desfavorecidas y en sujetos divorciados debido a problemas de malnutrición (27).

\section{Genética}

Se observa una predisposición asociada en caso de:

- Síndromes (mutaciones).

- Aumento de mutaciones del ADN.

- Dificultad en metabolizar carcinógenos.

- Dificultad de reparar el ADN (27).

\section{BASES MOLECULARES DEL CÁNCER ORAL}

La carcinogénesis es el mecanismo a través del cual se desarrolla una neoplasia maligna. Hay muchas 
lagunas en la literatura científica sobre este tema, si bien, poco a poco determinadas fases de la carcinogénesis van quedando esclarecidas.

La génesis y el desarrollo tumoral son el resultado de numerosas alteraciones moleculares que se producen en nuestro ADN y en donde están implicados los oncogenes, que a través de variaciones en su secuencia de nucleótidos adquieren capacidades generadoras de tumores. Los protooncogenes son secuencias génicas que codifican las proteínas que controlan el crecimiento y diferenciación celular. El resultado de la alteración de la secuencia génica del protooncogén, por mutación, amplificación o reordenamiento cromosómico, se conoce con el nombre de oncogén (28).

Los genes supresores tumorales son genes cuya activación protege a la célula de la adquisición de características malignas, actuando a nivel de diferentes puntos de chequeo del ciclo celular. La proteína del retinoblastoma (pRb) y su sistema molecular asociado se encuentran frecuente y precozmente alterados en el cáncer oral. Los genes que codifican las proteínas inhibidoras de las quinasas dependientes de ciclinas se comportan como importantes genes supresores tumorales, promoviendo un adecuado funcionamiento de $\mathrm{pRb}$ y por tanto un correcto control del ciclo celular. Uno de los genes supresores tumorales más importantes en el ser humano es el TP53. La supresión de las funciones de este gen y su sistema molecular asociado se observa en numerosos tumores humanos y constituye uno de los hallazgos más precoces en la historia natural del cáncer (29).

\section{MANIFESTACIONES CLÍNICAS DEL CÁNCER ORAL}

El cáncer oral en su manifestación clínica más frecuente, el carcinoma oral de células escamosas, puede pronunciarse siguiendo uno de estos dos caminos:

- "De novo", desarrollándose directamente a partir de mucosa sana.

- Siguiendo la secuencia: estado precanceroso (displasia epitelial)-carcinoma.

Aproximadamente un 50\% de los carcinomas epidermoides se desarrollan sobre un epitelio previamente alterado. En el Simposium Internacional de Uppsala, Axell T. y cols. definieron algunos conceptos básicos para entender la carcinogénesis oral. Así, entendemos por lesión precancerosa un tejido morfológicamente alterado en el cuál la aparición de cáncer es más probable que en su homólogo normal. Una condición precancerosa es un estado sistémico generalizado que predispone a un riesgo mayor de padecer cáncer. En la tabla 2 pueden observarse las distintas lesiones y condiciones precancerosas.

El potencial de malignización de estos estados llamados "potencialmente cancerosos" viene determinado por la presencia de displasia epitelial, entendiéndose por ésta la combinación variable de una serie de fenómenos microscópicos indicativos de un desorden de la maduración epitelial y una alteración de la proliferación celular (28).

En la biología del crecimiento tumoral se pueden distinguir cuatro fases bien definidas:

1. Alteración maligna de la célula diana: transformación.

2. Crecimiento de las células transformadas.

3. Invasión local.

4. Metástasis.

El tamaño del tumor depende del cociente producción/pérdidas. Cuantas más células hay en división,

TABLA 2.- LESIONES Y CONDICIONES PRECANCEROSAS (28)

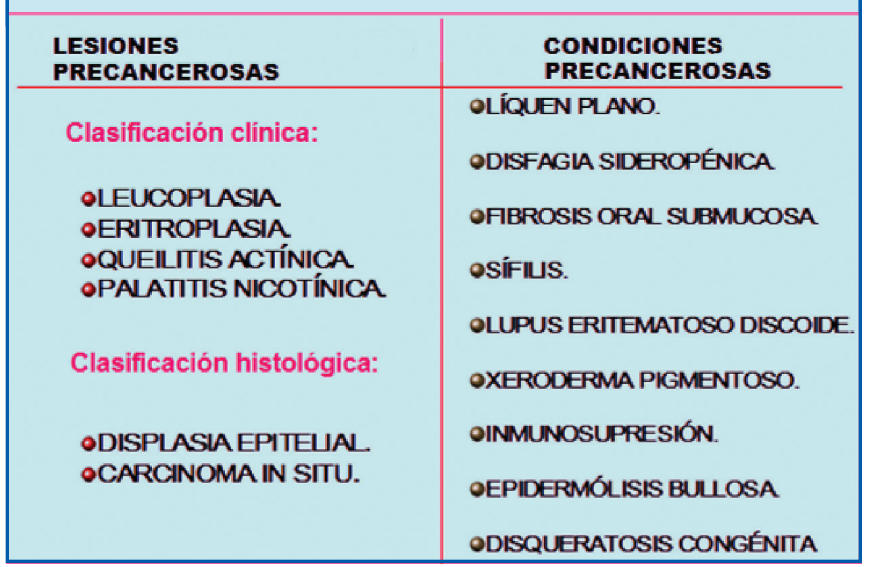


más sensibilidad a la quimioterapia. El crecimiento de las células transformadas se lleva a cabo gracias a los vasos sanguíneos que, por un lado, liberan factores de crecimiento y células liberadoras de factores de crecimiento y, por otro, sirven de fuente de nutrición. La invasión local depende de la agresividad y del potencial maligno del tumor. El cáncer aparece por transformación maligna de una sola célula y con el paso del tiempo se producirá "heterogeneidad tumoral" que hace referencia a la aparición de subclones con fenotipos diferentes de la célula primera originando una gran variedad de tipos celulares. La metástasis tumoral podría esquematizarse de la siguiente manera:

a) Invasión de la matriz extracelular.

b) Circulación por el torrente sanguíneo.

c) Depósitos secundarios en lugares alejados.

Atendiendo a la semejanza o ausencia de similitud con el epitelio malpighiano del que deriva, podemos clasificar los carcinomas orales en tres grados:

- Bien diferenciados: Histológicamente son muy similares al epitelio pavimentoso malpighiano del que derivan. Las células tumorales conservan la capacidad de formar queratina, formando perlas o globos córneos dentro de unos límites bien definidos. Las mitosis son moderadas y hay escasas atipias celulares. Frecuentemente aparece un infiltrado peritumoral.

- Moderadamente diferenciado: El número de mitosis aumenta y la queratinización celular va disminuyendo, dejando de formar globos córneos y queratinizándose células de forma aislada. El infiltrado tumoral va disminuyendo.

- Mal diferenciados o indiferenciados: Desaparece la actividad queratoblástica. Los clones celulares pierden su semejanza con las células de las que derivan y se rompe la adhesión intercelular facilitando las metástasis (30).

El hallazgo clínico más frecuente a nivel oral es el de una úlcera indurada, de bordes evertidos y en ocasiones dolorosa que, generalmente, se acompaña de adenopatías cervicales. En estadios más avanzados, el carcinoma epidermoide puede presentarse bajo tres formas clínicas:
- Morfología endofítica: conformando una úlcera irregular con bordes evertidos y fondo sucio.

- Morfología exofítica: de crecimiento tumoral vegetante, irregular e indurado a la palpación.

- Tipo mixto: formado por asociación de las dos formas anteriores (Figura 4).

En cuanto a la sintomatología, ésta puede estar ausente o manifestarse en un amplio rango (Tabla 3 ).

\section{DIAGNÓSTICO DEL CÁNCER ORAL}

El pronóstico y la supervivencia del paciente cambia radicalmente ante un diagnóstico precoz. De este

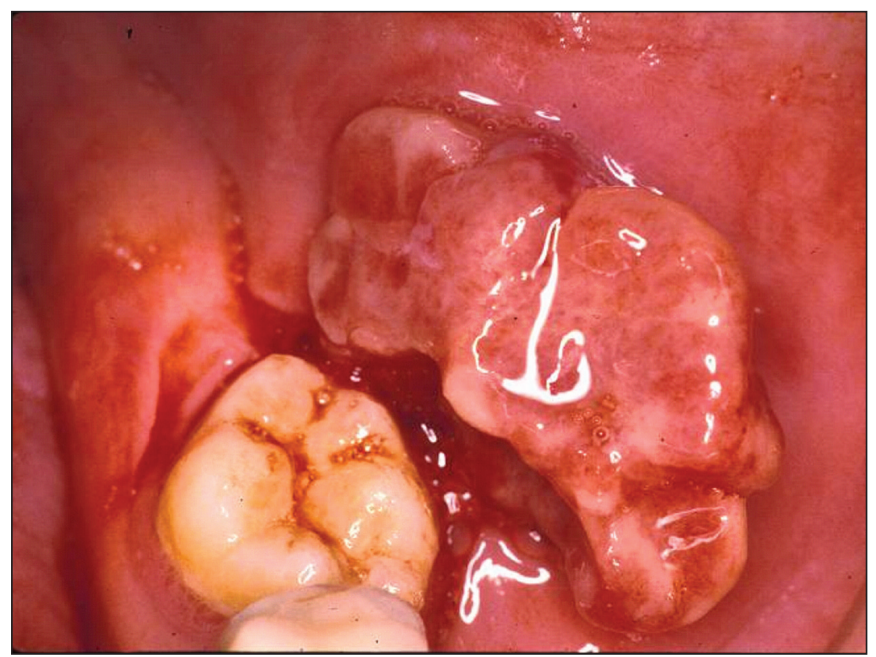

Fig. 4. Carcinoma Oral de células escamosas de tipo mixto. Cedida por el Dr. Antonio Bascones Martínez.

TABLA 3.- SÍNTOMAS RELACIONADOS CON EL CÁNCER ORAL

Sintomatología del cáncer oral

- Dolor o hipersensibilidad

Hemorragia

Cambio en la mordida

- Movilidad dentaria

- Mal ajuste de la dentadura

\& Restricción de la lengua

Cambio de roz

† Disfagia

- Sintomas de tumor primario

distante
- Cambio en el movimiento mandibular

EDisgeusia

- Cambio en la sensibilidad

Paresia o parálisis

- Diplopia

- Tos crónica

- Cambio en el habla 
modo, un examen sistemático de la mucosa oral, tanto por medios visuales como mediante la palpación digital, deben formar parte de todo examen dental rutinario. A continuación expondremos una sistemática a seguir en la revisión de nuestros pacientes:

1. Examen de los labios. La superficie externa debe estar libre de grietas o úlceras.

2. Examen del aspecto interno labial.

3. Examen de las cadenas ganglionarias de forma rutinaria: submental, cadenas submandibulares, cadenas cervicales y cadenas yugulodigástricas.

4. Visión global, atendiendo especialmente al tejido gingival y al vestíbulo.

5 . Examen de mucosa yugal.

6. Suelo de boca (zona de alto riesgo de malignización).

8. Examen de la superficie ventral de la lengua.

9. Examen de la superficie dorsal de la lengua.

10. Bordes laterales de la lengua (tomar la lengua con una gasa).

11. Visualización del paladar.

12. Retirar prótesis.

13. Examen velo paladar y pilares posteriores.

14. Examen orofaringe.

El diagnóstico definitivo de cáncer oral conlleva la realización de una biopsia para hacer un estudio anatomopatológico. Algunas herramientas utilizadas como coadyuvante a la biopsia son el azul de toluidina o la tinción con solución de lugol que ayudan a delimitar la zona idónea de resección, así como la citología exfoliativa o la biopsia por aspiración o por raspado (27).

Por otro lado, los avances científicos nos acercan a un punto donde el cáncer, en lugar de resultar una amenaza imprevisible, se va haciendo cada vez más previsible, más "conocido". Nos encontramos en la era de los marcadores tumorales que pueden ser detectados y medidos con las más modernas técnicas de inmunohistoquímica. Estos marcadores participan y nos informan de la proliferación celular y nos alarmarán precozmente sobre el comienzo de la malignización en un tejido. Dentro de los marcadores moleculares podemos distinguir:
- Marcadores de superficie: carbohidratos, antígenos de histocompatibilidad (HLA), factores y receptores de crecimiento, antígeno CD57 e integrinas, entre otros.

- Marcadores intracelulares: citoqueratinas, marcadores de queratinización anómala, cambios en el núcleo, oncogenes y genes supresores de tumores, productos del ácido araquidónico y enzimas, entre otros.

Se utilizan anticuerpos monoclonales y policlonales para poder detectar marcadores tisulares que nos informen tanto del \% de proliferación como de apoptosis existente en una determinada muestra de tejido perteneciente a una lesión cancerosa o precancerosa.

\section{TRATAMIENTO DEL CÁNCER ORAL}

Para facilitar el seguimiento clínico y terapéutico de los pacientes se emplea la clasificación TNM: T (Tamaño del tumor primario); N (Presencia de ganglios linfáticos); M (Metástasis a distancia). De una forma más desglosada las subdivisiones correspondientes son:

a) T1: Tumor menor o igual a $2 \mathrm{~cm}$; T2: Tumor mayor de $2 \mathrm{~cm}$ pero menor de $4 \mathrm{~cm}$; T3: Tumor mayor de $4 \mathrm{~cm}$; T4: El tumor invade estructuras adyacentes.

b) N0: No hay metástasis ganglionares; N1: Hay metástasis en un ganglio linfático homolateral menor o igual a $3 \mathrm{~cm}$; N2a: Metástasis en un ganglio homolateral mayor de $3 \mathrm{~cm}$ pero menor de 6; N2b: Metástasis en múltiples ganglios homolaterales, menores de $6 \mathrm{~cm}$; N3. Metástasis en un ganglio linfático mayor de $6 \mathrm{~cm}$.

c) M0: No hay metástasis a distancia; M1: Hay metástasis a distancia (31).

El factor más importante en la supervivencia es la etapa de la enfermedad en que se diagnostica. De forma práctica se establece el estadiaje tumoral que comprende:

- Estadio 1: T1 M0 NO.

- Estadio 2: T2 MO NO. 
- $\quad$ Estadio 3: T3 N0 M1; T1 N1 M0; T2 N1 M0; T3 N1 M0.

- Estadio 4: T4 MO N0; Tx M2-3 N0; Tx Nx M1.

Los estadios I y II engloban el período inicial, donde la tasa de supervivencia suele ser elevada, mientras que los estadios III y IV representan las fases avanzadas de la enfermedad, donde el pronóstico empeora drásticamente (31).

El tratamiento del paciente oncológico es multidisciplinar, siendo más agresivo y menos conservador cuanto más tarde se diagnostique la enfermedad. Es por ello que el siguiente punto que desarrollaremos es de vital importancia para la calidad de vida de las "víctimas" de un cáncer.

\section{PAPEL DEL DENTISTA EN LA PREVENCIÓN DEL CÁNCER ORAL}

La comunidad odontológica tiene la responsabilidad en la educación, detección precoz, el diagnóstico y la remisión al especialista de pacientes con cáncer oral. La boca es un área muy accesible por lo que la detección de lesiones o condiciones premalignas no es dificultosa.

El cumplimiento de esta responsabilidad por parte del odontólogo proporcionará una tasa de supervivencia mayor para nuestros pacientes y una marcada reducción en las tasas de morbilidad y mortalidad mundial (32).

\section{BIBLIOGRAFÍA}

1. Muñoz A. Cáncer. Genes y nuevas terapias. Madrid: Hélice.

2. A. Bascones, ed. Medicina bucal. Editorial Avances-ariel. 3ª edición. 2004.

3. AR. Ten Cate. Oral histology: Development safeEMYB, Inc. 1998.

4. Altman R, Sarg J. The cancer dictionary: revised edition. Checkmark Books, New York. $2^{\mathrm{a}}$ edición. 2000.
5. Hoffman HT, Karnell LH, Funk GF, Robinson RA, Menck HR. The National Cancer Data Base report on cancer of the head and neck. Arch Otolaryngol Head Neck Surg. 1998 Sep;124(9):951-62.

6. Jemal A, Tiwari RC, Murray T, Ghafoor A, Samuels A, Ward E, et al. Cancer statistics, 2004. CA Cancer J Clin. 2004 Jan-Feb;54(1):8-29.

7. Johnson NW. Orofacial neoplasms: global epidemiology, risk factors and recommendations for research. Int Dent J. 1991 Dec;41(6): 365-75.

8. World Health Organisation: the World Health Report.Geneve W. 1997.

9. Cáncer en España. Madrid: Misiterio de Sanidad y Consumo. 1993.

10. Edwards BK, Howe HL, Ries LA, Thun MJ, Rosenberg HM, Yancik R, et al. Annual report to the nation on the status of cancer, 1973-1999, featuring implications of age and aging on U.S. cancer burden. Cancer. 2002 May 15;94(10): 2766-92.

11. Silverman S, Jr. Demographics and occurrence of oral and pharyngeal cancers. The outcomes, the trends, the challenge. J Am Dent Assoc. 2001 Nov;132 Suppl:7S-11S.

12. Myers JN, Elkins T, Roberts D, Byers RM. Squamous cell carcinoma of the tongue in young adults: increasing incidence and factors that predict treatment outcomes. Otolaryngol Head Neck Surg. 2000 Jan;122(1):44-51.

13. Cáncer oral. Juan Carlos de Vicente Rodríguez. Inibsa y Fundación Central Española. 2007.

14. Krolls SO, Hoffman S. Squamous cell carcinoma of the oral soft tissues: a statistical analysis of 14,253 cases by age, sex, and race of patients. J Am Dent Assoc. 1976 Mar;92(3):571-4.

15. Rodu B, Jansson C. Smokeless tobacco and oral cancer: a review of the risks and determinants. Crit Rev Oral Biol Med. 2004;15(5):252-63. 
16. Gupta PC, Mehta FS, Daftary DK, Pindborg JJ, Bhonsle RB, Jalnawalla PN, et al. Incidence rates of oral cancer and natural history of oral precancerous lesions in a 10-year follow-up study of Indian villagers. Community Dent Oral Epidemiol. 1980;8(6):283-333.

17. Znaor A, Brennan P, Gajalakshmi V, Mathew A, Shanta V, Varghese $C$, et al. Independent and combined effects of tobacco smoking, chewing and alcohol drinking on the risk of oral, pharyngeal and esophageal cancers in Indian men. Int $\mathrm{J}$ Cancer. 2003 Jul 10;105(5): 681-6.

18. Du X, Squier CA, Kremer MJ, Wertz PW. Penetration of N-nitrosonornicotine (NNN) across oral mucosa in the presence of ethanol and nicotine. J Oral Pathol Med. 2000 Feb;29(2): 80-5.

19. Thomas DB. Alcohol as a cause of cancer. Environ Health Perspect. 1995 Nov; 103 Suppl 8: 153-60.

20. Hindle I, Downer MC, Moles DR, Speight PM. Is alcohol responsible for more intra-oral cancer? Oral Oncol. 2000 Jul;36(4):328-33.

21. Carretero Pelaez MA, Esparza Gomez GC, Figuero Ruiz E, Cerero Lapiedra R. Alcohol-containing mouthwashes and oral cancer. Critical analysis of literature. Med Oral. 2004 Mar-Apr;9(2):120-3, 16-20.

22. Divisi D, Di Tommaso S, Salvemini S, Garramone M, Crisci R. Diet and cancer. Acta Biomed. 2006 Aug;77(2):118-23.

23. van Breemen RB, Pajkovic N. Multitargeted therapy of cancer by lycopene. Cancer Lett. 2008 Jun 26.

24. Spadari F, Bruno E, Salvato A. (Oral cavity diseases in HIV and AIDS infections. Clinical, preventive and therapeutic aspects). Minerva Med. 1997 Nov;88(11):441-57.

25. Velly AM, Franco EL, Schlecht N, Pintos J, Kowalski LP, Oliveira BV, et al. Relationship between dental factors and risk of upper aerodigestive tract cancer. Oral Oncol. 1998 Jul;34(4):284-91.

26. Lockhart PB, Norris CM, Jr., Pulliam C. Dental factors in the genesis of squamous cell carcinoma of the oral cavity. Oral Oncol. 1998 Mar;34 (2):133-9.

27. Bascones A. SJM, Aguado A., suárez J.M. Cáncer y precáncer oral. Bases clínico-quirúrgicas y moleculares. Ediciones Avances. 1ª Edición. 2003.

28. García García V G-MM, Bascones Martínez A. Bases moleculares del cáncer oral.Revisión bibliográfica. Av.Odontoestomatol 2005;21-6:287295.

29. González-Moles MA G-MJ, Ruiz-Ávila. Bases moleculares de la cancerización de la cavidad oral. AvOdontoestomatol. 2008;24(1):55-60.

30. Bagán JV SC. Medicina y Patología Oral. 2006.

31. Sobin LH, Hermanek P, Hutter RV. TNM classification of malignant tumors. A comparison between the new (1987) and the old editions. Cancer. 1988 Jun 1;61(11):2310-4.

32. Chimenos Küstner E. Aspectos práctivos en la prevención del cáncer oral. Av. Odontoestomatol. 2008;24(1):61-7.

\section{CORRESPONDENCIA}

Virginia García García

eMail: virginiaborj@hotmail.com 